\title{
Effects of Job Satisfaction on Quality of Life for 119 Paramedics
}

\author{
Sungsoo Choi ${ }^{1}$ and Seongwoo Yun $^{2 *}$ \\ ${ }^{1}$ Department of Emergency Medical Service, Howon University \\ Gunsan, South Korea \\ [e-mail: ranger898@howon.ac.kr] \\ ${ }^{2}$ Department of Emergency Medical Service, Namseoul University \\ Cheonan, South Korea \\ [e-mail: smsympathy@ naver.com] \\ *Corresponding author: Seongwoo Yun
}

\begin{abstract}
The present study investigated the effects of work satisfaction on quality of life for 119 paramedics, the Korean equivalent of 911 paramedics. Data collection began in July 2017 and lasted for six months. Data was collected from 410119 paramedics of the J province and the G metropolitan area who consented to study participation. The results showed that the higher the job satisfaction of the participants, the higher the quality of life $(r=0.508, p=0.008)$. The factors affecting the quality of life were leisure activity, subjective health, and job satisfaction. For 119 paramedics to improve their quality of life, they need to relieve work stress and fatigue through leisure activities, and recover and maintain their health through sufficient rest. Moreover, returning to work in a healthy state likely leads to increased job satisfaction, and the quality of life will increase accordingly. Therefore, 119 paramedics should be permitted to have plenty of leisure time outside their work hours and should be able to maintain health through periodic health checks.
\end{abstract}

Keywords: Quality of life, 119 paramedics, Health, Fatigue, Leisure activity

A preliminary version of this paper was presented at APIC-IST 2018, and was selected as an outstanding paper. This study was conducted with the Scholarship and Research Fund of Howon University 


\section{Introduction}

119 paramedics are in charge og emergency medical services that protect the lives and property of the people through various accidents and incidents that are heard every year. Emergency services, which account for the largest portion of field work, are also the areas where firefighters are most avoied [1].

The 119 paramedics provide emergency medical services and have increasingly high workloads and risks. These include natural disasters, infectious diseases, and hazardous materials, such as explosive fragments and toxic fumes from fires. The equipment and the number of paramedics are not catching up to the demanding workload [2,3]. 119 paramedics are often exposed to life-threatening or dangerous situations. Some patients are dead on arrival, and others have serious conditions such as penetration wounds or limbs that are torn apart. Paramedics frequently witness patients die on the job at accident sites [3,4].

In addition, mental burdens and stresses are increasing due to the risk of accidents in the atmosphere and mobility in a tense environment [5].

This distressing work environment causes post-traumatic stress, leading to psychological conditions such as depression, panic attacks, and respiratory, cardiovascular, and musculoskeletal diseases [3]. The increased job stress has been associated with negative consequences like decreased job performance, illness, absenteeism, and turnover, which in turn negatively affects job satisfaction [6]. To relieve stress, they may frequently engage in unhealthy coping mechanisms such as drinking alcohol and coffee or smoking [7], affecting not only their quality of life during employment but also after retirement. These findings suggest that the quality of life of 119 paramedics is likely influenced by job satisfaction. Emergency sites have urgency and danger to change from time to time. Sometimes they feel the risk to their life, and they may be low in job satisfaction due to shift work and various administrative tasks.

The characteristics of the firefighting officer, the ability to perform as a pivotal role in the pre-hospital emergency medical services area, and at the same time, the maximum capability in a complex working environment are required [8].

Job satisfaction is defined as pleasant emotions and emotional satisfaction, including job itself, depending on the beliefs, attitudes, values, and desires of the individual. The person who feels job satisfaction maintains a good relationship with the outside and inside of the organization and it is possible to obtain an increase effect [9]. In addition, in the psychological state of an individual who has a positive attitude toward their job and a positive emotional state about their job life, the higher the job satisfaction, the more self-satisfaction, it helps to improve [10].

The quality of life is defined as the perceived level of satisfaction with the environmental conditions of life, and it is an index that describes the degree of human well-being by integrating social activities and economic environment besides physical and mental ones [11].

The characteristics of the firefighting officer, After experiencing a trauma, they experience below : a persistent and painful re-experience, avoidance of trauma-related stimuli, slowed emotional response, and symptoms of anxiety disorder. This post-traumatic stress not only causes mental problems but also causes physical problems, resulting in adverse effects on job performance, as well as alcohol and substance abuse and family conflict [12]. 119 paramedics with such stress disorder, are less satisfied with their job and experience various psychological 
and physiological stress reactions such as physical symptoms, substance abuse including mental disorders and drinking problems.

In the case of overseas cases, about one-third of Scottish paramedics showed mental pathology, burnout, and post-traumatic symptoms. In Germany, $18.2 \%$, in US $22.2 \%$, in Canada $17.3 \%$, and in Japan $17.7 \%$ of the firefighting officers showed higher stress than the general public [13]. Also, for many paramedics, acute and chronic stressors have had a lasting impact on psychological health. This was higher than that of the general public [14].

The quality of life of firefighters complains of anxiety and suicide is high. And at the sub-factor of quality of life, physical functioning, role limitation related to physical causes, physical pain, health perception, social role performance, and mental health status were low condition. In addition, the mental status, psychosocial stress, and they said that illness of firefighters is reported to be influential factors of quality of life $[15,16]$, job stress is the cause of burnout, and affects the quality of life [17]. Social support means that they are loved, cared, respected, and valued. And it can be said that is a result of meaningful interactions with family members or others[18]. In this way, it can be said that the factors of life can affect the growth of social support in the positive direction of the firefighting officers, and can alleviate the psychological and emotional factors caused by the stress.

Therefore, the present study was conducted with 119 paramedics to determine how their job satisfaction affects their quality of life. Furthermore, this study aimed to provide evidence for developing improvement measures for job satisfaction and quality of life in the future.

\section{Research Methods and Tools}

\subsection{Research subjects and data collection}

The study was conducted with 410119 paramedics of the J province and G metropolitan city, who agreed to participate in the study after the investigator briefed them on the study purpose assured confidentiality. The investigator's visit to the fire departments took place between July and December 2017. The questionnaire was distributed to the selected subjects and a self-reporting format was used. 397 questionnaires were used in the analysis of the study. 13 of the 410 questionnaires were not collected or missing. A survey was administered to the subjects for self-reporting, and 397 of 410 surveys were used in the analysis. Thirteen surveys were either not returned or included unanswered survey items.

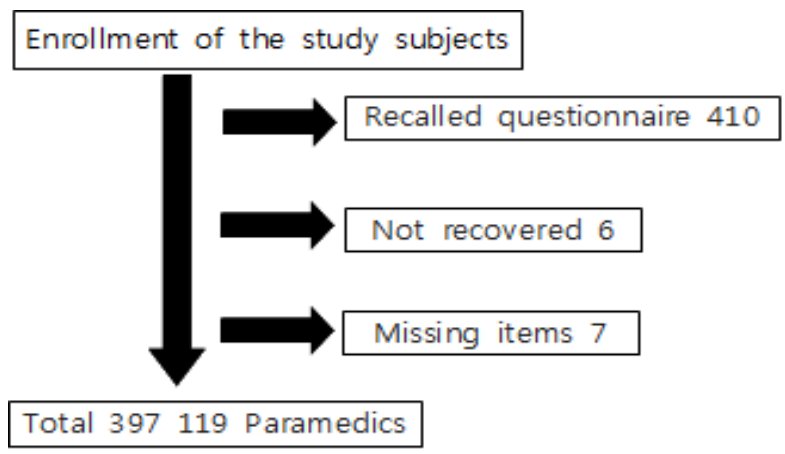

Fig. 1. Design of Research Subjects and Survey 


\subsection{Research Instrument}

\subsubsection{General Characteristics of Subjects}

General characteristics of subjects were assessed by 10 items: gender, age, education level, marriage, religion, license, duration of career, monthly income, leisure, and self-rated health status.

\subsubsection{Job satisfaction}

Job satisfaction was assessed with a questionnaire developed by modifying the measures used by Jo [15] and Choi et al [19]. The questionnaire consisted of seven domains and 33 items: six items in Compensation, six items in Pride, four items in Autonomy, two items in Responsibilities, six items in Cooperation and Collaboration, five items in Organizational Activities and Decision Making, and four items in Work Conditions. The items were scored on a 4-point Liker scale (1=very dissatisfied; $2=$ dissatisfied; $3=$ satisfied; $4=$ very satisfied). The maximum possible score was 132, and higher totals indicated a higher level of satisfaction with work. Reliability of the measure was Cronbach $\alpha=0.94$, while the reliabilities of the measures used in Jo [15] and Choi et al [19] were Cronbach $\alpha=0.92$ and Cronbach $\alpha=0.94$, respectively.

\subsubsection{Quality of life}

Quality of life was assessed with the Korean adaptation of the World Health Organization Quality of Life (WHOQOL-BREF) for use with paramedics. The WHOQOL-BREF was a brief version of WHOQOL-100 developed by World Health Organization (WHO). The WHOQOL-BREF was adapted to fit the Korean context and the validity and was evaluated on validity and reliability by Min et al [20]. The Korean version was modified by shin et al [7] for use with paramedics.

The modified Korean WHOQOL-BREF was comprised of four subscales and 26 items: seven items in Physical Domain, six items in Psychological Domain, three items in Social Domain, eight items in Living Environment Domain, and two items in Overall Quality of Life and Perceived Overall Health. The items were scored on a 5-point Likert scale (1=strongly disagree, $2=$ disagree, $3=$ neither agree nor disagree, $4=$ agree, $5=$ strongly agree). The inversely coded items were scored accordingly, and the total scores ranged between 26 and 130 points. The raw scores were used in the analysis, and higher scores indicated a higher quality of life. Reliability of the Korean version of the WHOQOL-BREF was Cronbach $\alpha=0.89$, and the reliability of its modified version was Cronbach $\alpha=0.93$ in Shin et al [7], and Cronbach $\alpha=0.92$ in the present study.

\subsection{Date analysis}

The collected data was analyzed using SPSS Statistics 21.1. Comparison of quality of life based on general characteristics and job satisfaction was conducted using a t-test and analysis of variance (ANOVA); the association between job satisfaction and quality of life was analyzed using a Pearson correlation. The factors affecting quality of life were identified by performing multiple linear regression analysis on the variables that were found to be significant in a simple regression analyses. Statistical tests were performed at the 0.05 significance level. General characteristics of research subjects are presented using descriptive statistics (frequencies and percentages), and job satisfaction and quality of life are presented using the means and standard deviations. 4. Experimental Classification Results and Analysis. The 
previous section identified three clusters for QoS classes and features to build up classification rules through unsupervised learning. In this section, the accuracy of the classification rules is evaluated experimentally. For classification, we chose the K-nearest neighbor (KNN) algorithm. Experimental results are compared with the minimum mean distance (MMD) classifier.

\section{Survey Results and Analysis}

\subsection{General characteristics of research subjects}

General characteristics of research subjects are described as follows. Regarding gender, 319 (78.1\%) were men and 87 (21.9\%) were women. Regarding age, 212 (53.4\%) were between the ages of 30 and $40,124(31.2 \%)$ were age 40 or older, and $61(15.4 \%)$ were younger than 30 . Regarding education level, 23 (5.8\%) were high school graduates, $117(29.5 \%)$ received a four-year college or more education, and 257 (64.7\%) were two-year college graduates. Regarding marital status, 105 (26.4\%) were single and 292 (73.6\%) were married. Regarding religion, 104 (26.2) were Christians, 40 (10.1) were Buddhists, 27 (6.8\%) were Roman Catholics, and 226 (56.9) chose "Other". 218 participants (54.9\%) had a level 1 EMT license, $134(33.8 \%)$ had a level 2 EMT license, and $45(11.3 \%)$ had a nursing license. Regarding duration of career, $240(60.5 \%)$ had less than 5 years of experience, while $157(39.5 \%)$ had five or more years of experience. Regarding monthly salary, 257 (64.7\%) received less than 3 million KRW, while $140(35.3 \%)$ received 3 million or more KWR. Regarding leisure activities, $339(85.4 \%)$ engaged in them, while $58(14.6 \%)$ did not. Regarding subjective health, $210(52.9 \%)$ indicated fair, $146(36.8 \%)$ indicated good, and $41(10.3 \%)$ indicated poor in Fig. 2, Table 1.

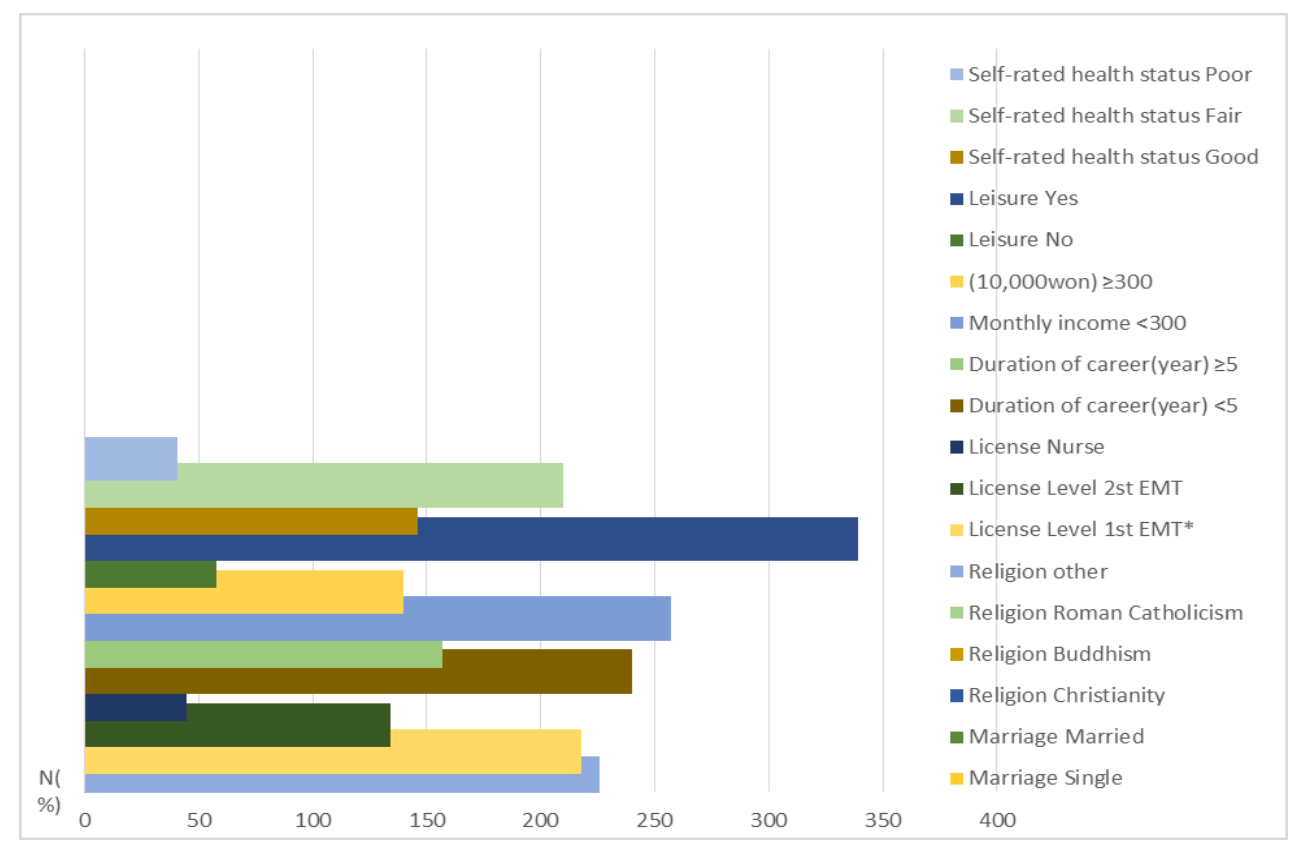

Fig. 2. 10 results graphs according to the common characteristics of targets 
Table 1. General characteristics

\begin{tabular}{|c|c|c|}
\hline Characteristics & Category & $\mathrm{N}(\%)$ \\
\hline \multirow{2}{*}{ Gender } & Male & $310(78.1)$ \\
\hline & Female & $87(21.9)$ \\
\hline \multirow{3}{*}{ Age(year) } & $<30$ & $61(15.4)$ \\
\hline & $30-<40$ & $212(53.4)$ \\
\hline & $\geq 40$ & $124(31.2)$ \\
\hline \multirow{3}{*}{ Education level } & High school & $23(5.8)$ \\
\hline & College & $257(64.7)$ \\
\hline & University & $117(29.5)$ \\
\hline \multirow{2}{*}{ Marriage } & Single & $105(26.4)$ \\
\hline & Married & 292(73.6) \\
\hline \multirow{4}{*}{ Religion } & Christianity & $104(26.2)$ \\
\hline & Buddhism & $40(10.1)$ \\
\hline & Roman Catholicism & $27(6.8)$ \\
\hline & other & $226(56.9)$ \\
\hline \multirow{3}{*}{ License } & Level 1st EMT* & $218(54.9)$ \\
\hline & Level 2st EMT & $134(33.8)$ \\
\hline & Nurse & $45(11.3)$ \\
\hline \multirow{2}{*}{ Duration of career(year) } & $<5$ & $240(60.5)$ \\
\hline & $\geq 5$ & $157(39.5)$ \\
\hline \multirow{2}{*}{$\begin{array}{l}\text { Monthly income } \\
(10,000 \text { won })\end{array}$} & $<300$ & $257(64.7)$ \\
\hline & $\geq 300$ & $140(35.3)$ \\
\hline \multirow{2}{*}{ Leisure } & No & $58(14.6)$ \\
\hline & Yes & $339(85.4)$ \\
\hline \multirow{3}{*}{ Self-rated health status } & Good & $146(36.8)$ \\
\hline & Fair & $210(52.9)$ \\
\hline & Poor & $41(10.3)$ \\
\hline
\end{tabular}




\subsection{Job satisfaction and quality of life of research subjects}

The mean score for job satisfaction was $85.31 \pm 13.55$ out of the maximum possible score of 132. The highest and the lowest scores of the subjects were 132 and 33, respectively. The mean score for quality of life was $79.08 \pm 12.08$ out of the possible maximum score of 110 . The highest and the lowest scores were 110 and 43, respectively in Table 2, Fig. 3.

Table 2. Job satisfaction and quality of life

\begin{tabular}{|c|c|c|c|}
\hline & M \pm SD & Min & Max \\
\hline \hline Job satisfaction & $85.31 \pm 13.55$ & 33 & 132 \\
\hline Quality of life & $79.08 \pm 12.08$ & 43 & 110 \\
\hline
\end{tabular}

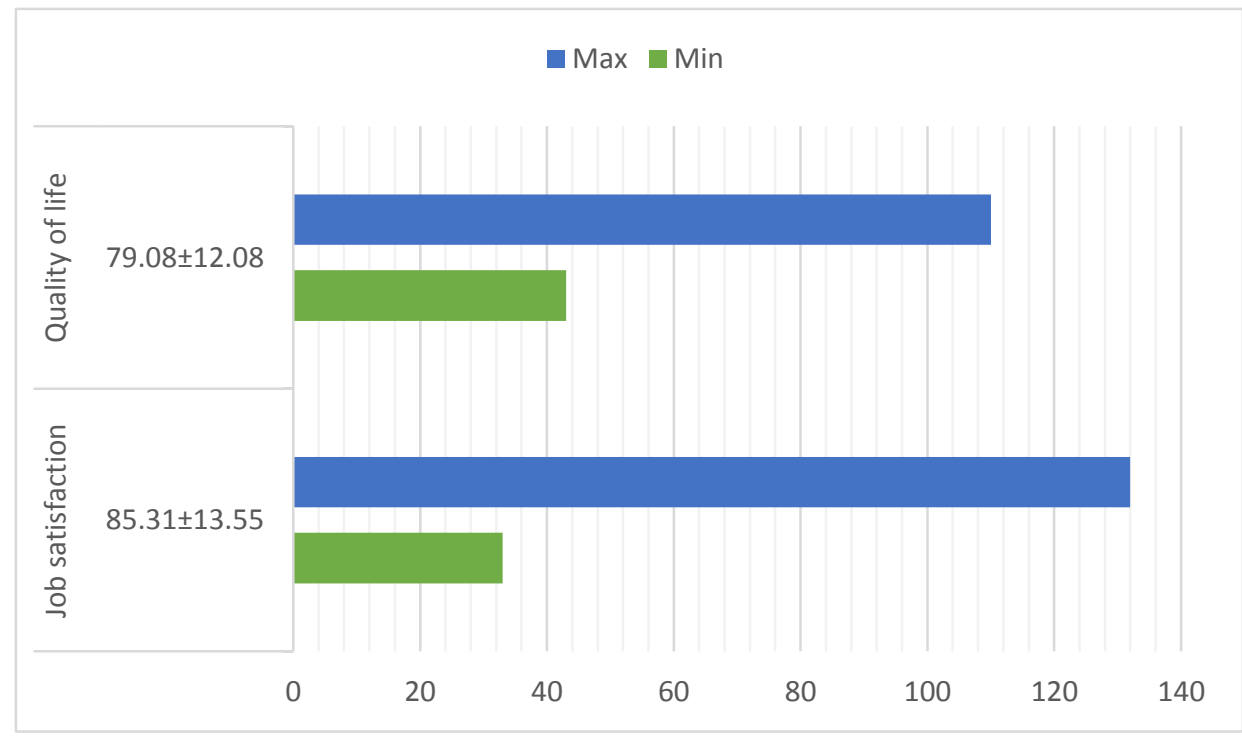

Fig. 3. Job satisfaction is composed of 33 questions in total of 7 areas and graph of results using the Likert scale. Quality of life consisted of 26 questions in 4 areas and graph of results using Likert scale

\subsection{Quality of life by general characteristics}

The results of the quality of life comparison by general characteristics showed a significant difference $(\mathrm{p}=0.011)$ in quality of life mean scores between age categories: younger than 30 scored at $83.28 \pm 11.28,30$ to 40 scored at $78.58 \pm 12.40$, and older than 40 scored at $7.87 \pm 11.54$. [Table 3]. Quality of life mean scores also significantly varied $(\mathrm{p}=0.001)$ between the two categories of career duration: $80.76 \pm 11.94$ for those with less than five years of experience and $76.50 \pm 11.86$ for those with five or more years of experience.

The mean scores also significantly varied $(\mathrm{p}=0.003)$ between those who engage in leisure activities (79.75 \pm 12.24$)$ and those who do not $(75.16 \pm 10.35)$. Regarding subjective health, there was also a significant difference between three groups: $83.92 \pm 11.83$ for good health, $76.89 \pm 11.51$ for fair, and $73.05 \pm 9.79$ for poor $(\mathrm{p}<0.001)$. Quality of life was not significant different between different groups based on gender, education level, marital status, religion, license type, or monthly salary in Table 3, Fig. 4. 
Table 3. Subjective by quality life

\begin{tabular}{|c|c|c|c|c|}
\hline \multirow{2}{*}{ Characteristics } & \multirow{2}{*}{ Category } & \multicolumn{3}{|c|}{ Quality of life } \\
\hline & & $\mathbf{M} \pm$ SD & t or $F$ & $\mathbf{p}$ \\
\hline \multirow{2}{*}{ Gender } & Male & $79.33 \pm 12.24$ & 0.799 & 0.426 \\
\hline & Female & $78.20 \pm 11.49$ & & \\
\hline \multirow{3}{*}{ Age(year) } & $<30$ & $83.28 \pm 11.28$ & 4.571 & 0.011 \\
\hline & $30-<40$ & $78.58 \pm 12.40$ & & \\
\hline & $\geq 40$ & $77.87 \pm 11.54$ & & \\
\hline \multirow{3}{*}{ Education level } & High school & $77.48 \pm 9.90$ & 0.568 & 0.567 \\
\hline & College & $78.82 \pm 12.33$ & & \\
\hline & University & $79.96 \pm 11.93$ & & \\
\hline \multirow{2}{*}{ Marriage } & Single & $80.25 \pm 13.63$ & 1.157 & 0.248 \\
\hline & Married & $78.66 \pm 11.46$ & & \\
\hline \multirow{4}{*}{ Religion } & Christianity & $78.86 \pm 10.77$ & 0.978 & 0.403 \\
\hline & Buddhism & $77.90 \pm 8.56$ & & \\
\hline & Roman Catholicism & $75.96 \pm 13.00$ & & \\
\hline & other & $79.76 \pm 13.02$ & & \\
\hline \multirow{3}{*}{ License } & Level 1st EMT* & $79.61 \pm 12.26$ & 0.739 & 0.478 \\
\hline & Level 2st EMT & $78.04 \pm 11.81$ & & \\
\hline & Nurse & $79.58 \pm 12.02$ & & \\
\hline \multirow{2}{*}{$\begin{array}{l}\text { Duration of } \\
\text { career(year) }\end{array}$} & $<5$ & $80.76 \pm 11.94$ & 3.488 & 0.001 \\
\hline & $\geq 5$ & $76.50 \pm 11.86$ & & \\
\hline \multirow{2}{*}{$\begin{array}{l}\text { Monthly income } \\
\text { (10,000won) }\end{array}$} & $<300$ & $79.21 \pm 12.59$ & 0.315 & 0.753 \\
\hline & $\geq 300$ & $78.83 \pm 11.11$ & & \\
\hline \multirow{2}{*}{ Leisure } & No & $75.16 \pm 10.35$ & -3.037 & 0.003 \\
\hline & Yes & $79.75 \pm 12.24$ & & \\
\hline \multirow{3}{*}{$\begin{array}{l}\text { Self-rated health } \\
\text { status }\end{array}$} & Good & $83.92 \pm 11.83$ & 22.523 & $<0.001$ \\
\hline & Fair & $76.89 \pm 11.51$ & & \\
\hline & Poor & $73.05 \pm 9.79$ & & \\
\hline
\end{tabular}




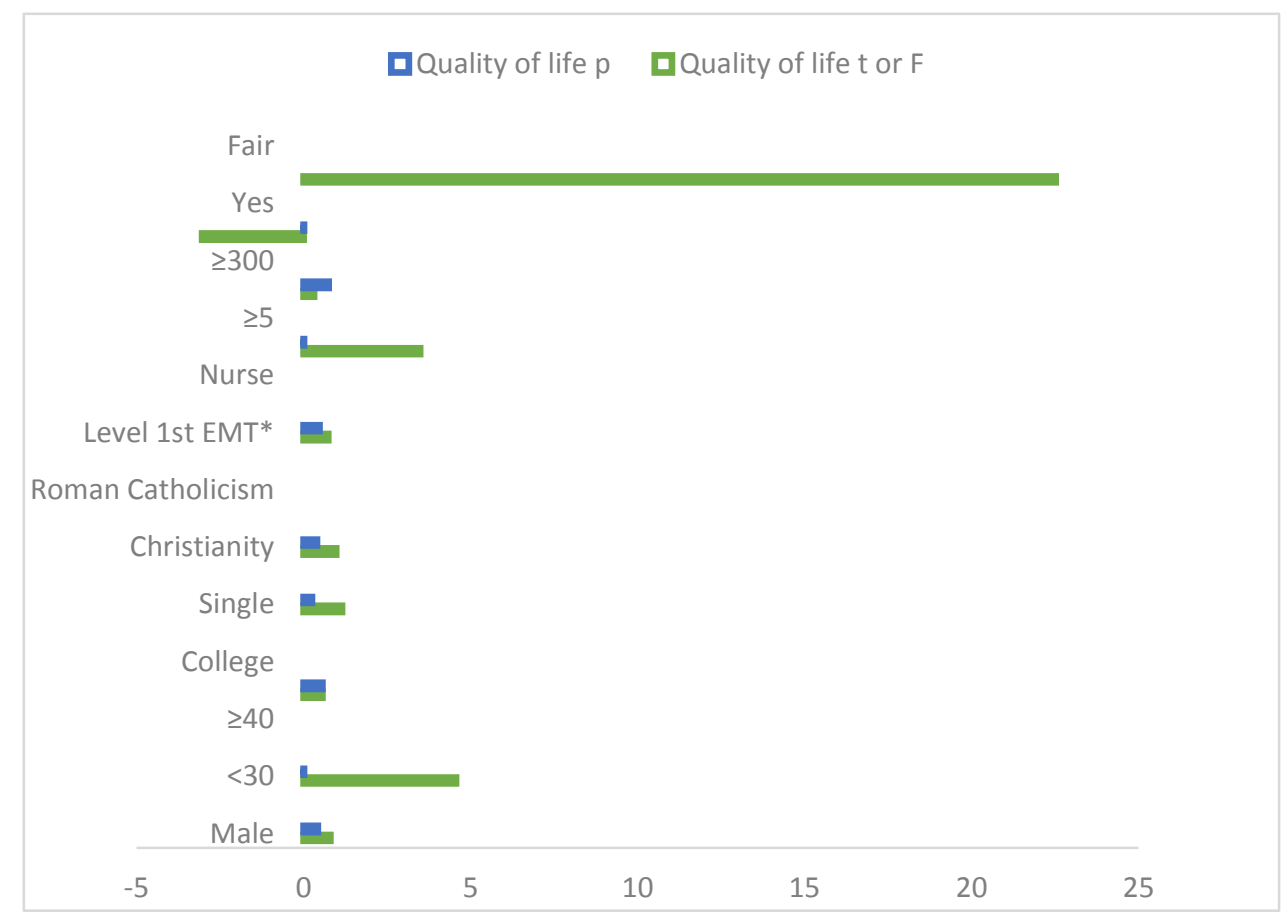

Fig. 4. Graph on the Quality of Life according to General Characteristics

\subsection{Correlation between job satisfaction and quality of life}

Job satisfaction and quality of life showed a significant positive correlation $(\mathrm{r}=0.508$, $p=<0.008$ ), indicating that those with a higher level of job satisfaction have a higher quality of life in Table 4.

Table 4. The correlation between job satisfaction and quality of life

\begin{tabular}{|c|c|c|}
\hline \multirow{2}{*}{} & \multicolumn{2}{|c|}{ Quality of life } \\
\cline { 2 - 3 } & $\mathbf{r}$ & $\mathbf{p}$ \\
\hline \hline Job satisfaction & 0.508 & 0.008 \\
\hline
\end{tabular}

Fig. 5. Graph of the correlation between the subject's job satisfaction and quality of life

\subsection{Factors affecting quality of life}

The results of multiple regression analysis performed to identify factors affecting quality of life are described as follows. Quality of life scores were significantly higher for those engaging in leisure activities $(\beta=3.216, p=0.028)$ than their counterparts. Quality of life scores were significantly lower for those who rated their health status as fair $(\beta=-4.648, p<0.001)$ or poor $(\beta=-3.415, p=0.001)$ than those who rated their health status as good. Quality of life scores were significantly higher for those with a higher level of job satisfaction $(\beta=0.399$, 
$\mathrm{p}<0.001)$. Explanatory power ( $\mathrm{R} 2)$ of the model was $31.8 \%(\mathrm{~F}=25.879, \mathrm{p}<0.001)$ in Table 5, Fig. 5.

Table 5. Factors influencing quality of life by multiple regression analysis

\begin{tabular}{|c|c|c|c|c|}
\hline Characteristics & Category & B & $\mathbf{~}$ & $\mathbf{p}$ \\
\hline \hline \multirow{2}{*}{ Age(year) $(/<30)$} & $30-<40$ & -0.470 & -0.274 & 0.784 \\
\cline { 2 - 5 } & $\geq 40$ & -0.542 & -0.467 & 0.641 \\
\hline $\begin{array}{c}\text { Duration of } \\
\text { career(year)(/<5) }\end{array}$ & $\geq 5$ & -2.051 & -1.839 & 0.067 \\
\hline $\begin{array}{c}\text { Leisure(/No) } \\
\text { Self-rated health } \\
\text { status(/Good) }\end{array}$ & Yes & 3.216 & 2.210 & 0.028 \\
\cline { 2 - 5 } & Fair & -4.648 & -4.127 & $<0.001$ \\
\hline \multicolumn{2}{c|}{ Job satisfaction } & -6.370 & -3.415 & 0.001 \\
\hline $\mathrm{R}^{2}=0.318(\mathrm{~F}=25.879, \mathrm{p}=<0.001)$ & 0.399 & 10.151 & $<0.001$ \\
\hline
\end{tabular}

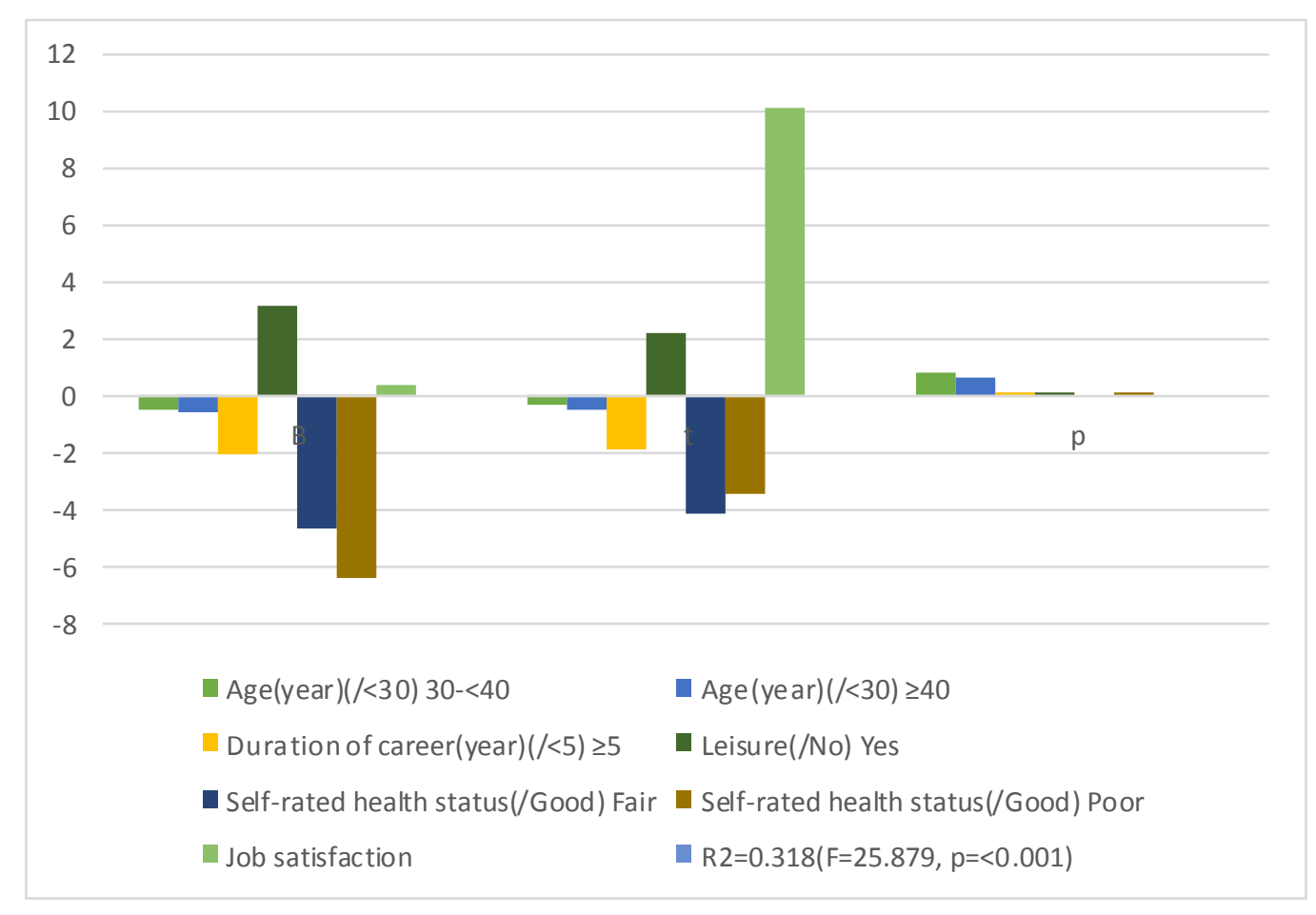

Fig. 5. Graphs on the Factors Affecting the Quality of Life of the Subject 


\section{Discussion}

Firefighters are playing a big role in public order and welfare by protecting the lives and property of the people through rescue and emergency services in urgent situations such as disasters and emergency sites. Among them, the first aid work occupies a large part of the work in the field of firefighting, and it is the most avoided field due to the high stress caused by frequent moods as well as atmospheric conditions [21]. In order to cope with many types of accidents and emergency situations directly related to life, their job satisfaction can be lowered by the mental burden and stress of 119 paramedics engaged in work in a tense field. The present study was conducted to determine job satisfaction of 119 paramedics and its effects on their quality of life.

Job satisfaction is defined as pleasant emotions and emotional satisfaction, including job itself, depending on the beliefs, attitudes, values, and desires of the individual. The person who feels job satisfaction maintains a good relationship with the outside and inside of the organization and it is possible to obtain an increase effect [9]. The results showed that the mean score of 119 paramedics' job satisfaction was $85.31 \pm 13.55$ out of the possible maximum score of 132 . This mean score was similar to that obtained by Choi et al. (85.19 \pm 13.37$)$ from 119 paramedics of the J province and $\mathrm{G}$ metropolitan city. Regarding factors affecting job satisfaction, the results of the present study showed age, career duration, leisure, and self-rated health status as significant factors. In terms of age, job satisfaction was highest among those younger than 30 (83.28 \pm 11.28 ), and lowest among those aged 40 or older $(77.87 \pm 11.54)$. In terms of duration of career, job satisfaction was higher among those with less than five years of experience $(80.76 \pm 11.94)$ than those with five or more years of experience $(76.50 \pm 11.86)$. In other words, those who are younger and have less than five years of work experience as a paramedic had a higher level of job satisfaction. The higher level of job satisfaction among the population likely reflects the following: Level 1 EMT and nurses find being a 119 paramedic desirable due to the job stability as a civil servant after college graduation and the advantage of utilizing their knowledge and skills [19], they have a strong sense of pride and accomplishment about becoming a 119 paramedic through a civil servant exam [22]. In terms of leisure activity status, job satisfaction was higher among those who engaged in leisure activities $(79.75 \pm 12.24)$ than those who do not. Those who engaged in leisure activities likely had a higher level of job satisfaction because they could relieve job stress and fatigue through these activities and could concentrate on work during work hours. Regarding self-rated health status, job satisfaction was highest among those with good subjective health $(83.92 \pm 11.83)$ and lowest among those with poor subjective health (73.05 \pm 9.79$)$. Those who feel they are unhealthy likely have a lower level of job satisfaction as they experience a higher level of job stress because they feel helpless, burn out, and anxious more frequently [7,23]. Furthermore, they experience chronic job stress due to an accumulation of fatigue and depletion of physical strength [19]. In order to cope with many types of accidents and emergency situations directly related to life, their job satisfaction can be lowered by the mental burden and stress of 119 paramedics engaged in work in a tense field. The factors influencing the quality of life of 119 paramedics were engagement in leisure activity, self-rated health status, and job satisfaction. Quality of life was higher among those with leisure activities than those without them $(\beta=3.216, p=0.028)$. Leisure activities allow freedom from the daily routine to utilize personal time to partake in cultural and artistic endeavors including restoring health, taking a rest, and engaging in hobbies. Spending time doing leisure activities likely increases job satisfaction as well as quality of life. Regarding self-rated health status, quality of life was lower among those with fair $(\beta=-4.648, p=<0.001)$ and poor subjective health $(\beta=-6.370, p=0.001)$ than those with good subjective health. Those with poorer health likely experience fatigue easily and a high 
level of job stress, leading to feelings of helplessness and burn out more often [23, 24]. This in turn negatively affects work and achievement, ultimately influencing quality of life. Regarding the relationship between job satisfaction and quality of life, a higher level of job satisfaction was associated with a higher quality of life $(\beta=0.399, p=<0.001)$. Among the factors affecting job satisfaction, the status of leisure activity and self-rated health status also influenced quality of life, and the correlation between job satisfaction and quality of life was significantly positive $(\mathrm{r}=0.508, \mathrm{p}=0.008)$.

In the physical, mental, and socioeconomic areas, subjective well-being of each individual is defined as quality of life, it including emotional state, economic life, physical symptoms, family support and social activity, and health [25]. The problem of measuring quality of life depends on what you see as important factors affecting quality of life. Thus, an objective indicator approach is meant to identify objective conditions that are thought to affect quality of life and to measure the extent to which those conditions are met.

These findings suggest that leisure activities relieve job stress, restore health, and provide opportunities for recuperation, enabling 119 paramedics to stay healthy, which in turn likely improve their job satisfaction, and enhance their quality of life.

This study has the following limitations: the study has limited generalizability of the study findings because study subjects were recruited from only two regions, and the cross-sectional research design does not allow clear determination of causality between factors and job satisfaction and quality of life. Despite the limitations, this study provides the evidence base for developing a program to improve job satisfaction and quality for 119 paramedics in the future by identifying the factors that affect job satisfaction and quality of life. Also, it is necessary to develop a job stress and health care program centering on 119 paramedics, and to be able to carry out effective first aid in the field, and propose a study to identify various variables affecting the quality of life of 119 paramedics do.

\section{Conclusions}

The present study was conducted to determine 119 paramedics' job satisfaction and its effects on their quality of life. In addition, paramedics are working together with internal work, various training, and administrative work in addition to emergency services, and the physical fatigue and mental stress caused by the work load increase, and the job satisfaction as a paramedic becomes low. For this reason, there is a possibility of causing deterioration of health condition and a more dangerous situation. Factors influencing job satisfaction were age, career duration, leisure activity, and self-rated health status. A higher level of job satisfaction was associated with a higher quality of life. Moreover, factors influencing quality of life were leisure activity, self-rated health status, and job satisfaction. The factors that influenced both job satisfaction and quality of life were leisure activity and self-rated health status. These results suggest that leisure activities likely relieve job stress and fatigue, and restore health, helping paramedics stay healthy, improve job satisfaction, and enhance quality of life.

\section{References}

[1] J. H. Kim, D. C. Uhm, E. A. Kim, "Correlation between violence, Burn-out, and Self-esteem of 119 rescue works," Journal of the Korea Academia-Industrial cooperation Society, vol. 11, no. 11, pp. 4433-4440, November, 2010. Article (CrossRef Link)

[2] Guidotti, TL, "Human factors in firefighting: ergonomic-, cardiopulmonary-, and psychogenic stress-related issues," Int Arch Occup Environ Health, vol. 64, no. 1, pp. 1-12, January 1992. 
Article (CrossRef Link)

[3] S. C. Kwon, J. C. Song, S. J. Lee, I. A. Kim, J. W. Koh, H. C. Ryou, H. S. Kim, D. H. Kim, S. A. Jung, "Posttraumatic stress symptoms and related factors in firefighters of a fire station," Ann Occup Environ Med, vol. 20, no. 3, pp. 193-204, September, 2008. Article (CrossRef Link)

[4] Carlier. IV, Voerman. AE, Gersons, BP, "The influence of occupational on post-traumatic stress symptomatology in traumatized police officers," British Journal of Medical Psychology, vol. 73, no. 1, pp. 87-98, 2000. Article (CrossRef Link)

[5] Y. R. Park, "Knowledge, Attitude and Self-Confidence of Student Nurses Regarding Nosocomial Infection Control," Journal of Korean Academy of Fundamentals of Nursing, Vol. 14, No. 4, pp. 429-436, November, 2007. Article (CrossRef Link)

[6] S. B. Joo and C. H. Lee, "A study on gender differences of relationship between PTSD perception and job satisfaction focused on Korea coast guard officers," Korean Journal of Victimology, vol. 21, no. 2, pp. 335-362, March, 2013. Article (CrossRef Link)

[7] K. S. Park, Y. O. Ha, M. J. Seo, Y. S. Choi, M. J. Kim, Y. J. Jeong, S. K. Yang, "Impact of Health-related Quality of Life in Firefighters: Focused on Posttraumatic Stress, Health-related Work Limitations, and Family Support," The Korean Journal of Occupational Health Nursing, vol. 26, no. 3, pp. 142-150, August, 2017. Article (CrossRef Link)

[8] A. Gown, "Current issues in ER and HER2 testing by IHC in breast cancer," Modern Pathology, vol. 21, no. S2, pp. s8-s15, May, 2008. Article (CrossRef Link)

[9] K. H. Kim, "Study on the relationship between the job satisfaction and turnover intension of the employees in travel agencies," The Korean Academic Society of Culture \& Tourism, vol. 9. No. 1, pp. 113-126, June 2017. Article (CrossRef Link)

[10] G. S. Bae, "The relationship between the job satisfaction the turnover intention of 119 emergency medical technicians," Korean J Emerg Med Ser, vol. 14, no. 1, pp. 65-80, April 2010. Article (CrossRef Link)

[11] Y. J. Nho and C. G. Kim, "Comparisons of physical fitness, self-efficacy, instrumental activities of daily living, and quality of life between institutionalized and noninstitutionalized elderly," Journal of Korean Academy of Nursing, vol. 25, no. 2, pp. 259-278, June, 1995. Article (CrossRef Link)

[12] A. Marie, J. Moiioy, M. Magaldi, "Health responses of newyork city firefighter spouses and their families post-september 11, 2001 terrorist attacks," Issues in Mental Health Nursing, Vol. 27, No. 8, pp. 905-917, October, 2006. Article (CrossRef Link)

[13] A. David, K. Susan, "Ambulance personnel and critical incidents: Impact of accident and emergency work on mental health and emotional well-being," The British Journal of Psychiatry, Vol. 178, No. 1, pp. 76-81, January, 2001.

[14] E. Ploeg, RJ. Kleber, "Acute and chronic job stress among ambulance personnel: predictors of health symptoms," Occupational Environmental Medicine, Vol. 60, No. 1, pp. 40-46, June, 2003. Article (CrossRef Link)

[15] H. T. Jo, "Work stress on satisfaction of emergency medical technicians working in national emergency management agency and hospital," Korean Journal of Occupational Health Nursing, vol. 22, no. 2, pp. 295-304, September, 2013. Article (CrossRef Link)

[16] YS. Chen, MC. Chen, FH. Chou, FC. Sun, PC. Chen, KY. Tsai, SS. Chao, "The relationship between quality of life and posttraumatic stress disorder or major depression for firefighters in Kaohsiung, Taiwan," Quality of Life Research, Vol. 16, No. 8, pp.1289-1297, October, 2007. Article (CrossRef Link)

[17] G. Prati, L. Pietrantoni, E. Cicognani, "Coping strategies and collective efficacy as mediators between stress appraisal and quality of life among rescue works," American Psychological Association, Vol. 18, No. 2, pp. 181-195, May, 2011. Article (CrossRef Link)

[18] LP. Johannes, R. Sebastiaan, "Work-related well-being of emergency workers in Gauteng," South African Journal of Psychology, Vol. 36, No. 1, pp. 63-81, March, 2006. Article (CrossRef Link)

[19] S. S. Choi, M. A. Han, J. Park, S. Y. Ryu, S. W. Choi, H. R. Kim, "Impact of job-related characteristics and post-traumatic stress on job satisfaction among 119 rescue crews," J Korean Soc Emerg Med, vol.26, no. 4, pp. 286-296, August, 2015. Article (CrossRef Link) 
[20] S. k. Min, C. I. Lee, K. I. Kim, S. Y. Suh, D. k. Kim, "Development of Korean version of WHO quality of life scale abbreviated version(WHOQOL-BREF)," J Korean neuropsychiatric Association, vol. 39, no. 2, pp. 571-579, May, 2000. Article (CrossRef Link)

[21] S. J. Choo, O. L. Park, H. S. Kang, "The factors influencing empowerment of 119 emergency medical technicians," The Korean Journal of Occupational Health Nursing, vol. 20, no. 2, pp. 153-162, August, 2011. Article (CrossRef Link)

[22] G. Y. Lee and E. S. Choi, "The perception types of clinical training experience in paramedics students," The Korean Society of Emergency Medical, vol. 21, no. 1, pp. 59-73, April, 2017. Article (CrossRef Link)

[23] G. Y. Park and K. T. Park, "Influence of job Environment, Job stress, and Fatigue on Job Satisfaction of Nurse: focused on Medical Treatment Departments of General Hospital," Journal of Korea Service Management Society, vol. 13, no. 5, pp. 59-79, December, 2012. Article (CrossRef Link)

[24] S. W. Hong, D. C. Eom, M. H. Jeon, "Job Stress and Work-Related Musculoskeletal Symptoms 0f 119 Emergency Medical Technicians," Korean Journal of Occupational Health Nursing, vol. 19, no.2, pp. 223-235, October, 2010. Article (CrossRef Link)

[25] Y. S. Choi and B. J. Cho, "The effects of leisure attitude on leisure satisfaction and job satisfaction: The case of nurse," Korea Journal of Tourism and Hospitality Research, vol. 26, no. 1, pp. 249-266, January, 2012. Article (CrossRef Link)

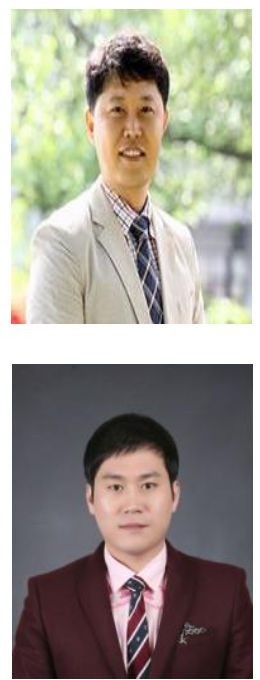

Sung Soo Choi received the B.S., M.S. degrees in department of emergency medical service from Chosun University Korea in 2010 and 2012 respectively and Ph. D. degree in Health Science from Chosun National University, Korea, in 2015. Dr. Choi joined the Department of Chonnam National University Hospital, gwangju in 2007. He is currently a Professor in the Department of emergency medical service, Howon University. He is American Heart Association BLS Training Center Faculty.

Seong woo Yun received the B.S., M.S. degrees in department of emergency medical service from Kongju National University Korea in 2009 and 2011 respectively and Ph. D. degree in Health Science from Chosun National University, Korea, in 2014. Dr. Yun joined the Department of Chonnam National University Hospital, gwangju in 2009. He is currently a Professor in the Department of emergency medical service, Namseoul University. He is interested in CPR. simulation experiment, and prehospital treatment. 